\title{
The Normal Ratio of Th17 and Th1 Post-mesenchymal Stem Cells Coculture with PBMCs of Systemic Lupus Erythematosus Patients
}

\author{
Azizah Retno Kustiyah ${ }^{1,2}$, Agung Putra ${ }^{3,4,5 *}$, Taufiqurrachman Nasihun ${ }^{4}$, Rajesh Ramasamy ${ }^{6}$ \\ ${ }^{1}$ Student of Postgraduate Biomedical Science, Faculty of Medicine, Universitas Islam Sultan Agung, Semarang, Indonesia; \\ ${ }^{2}$ Department of Pediatric, Faculty of Medicine, Universitas Islam Sultan Agung, Semarang, Indonesia; ${ }^{3}$ Stem Cell and Cancer \\ Research, Faculty of Medicine, Universitas Islam Sultan Agung, Semarang, Indonesia; ${ }^{4}$ Department of Postgraduate Biomedical \\ Science, Faculty of Medicine, Universitas Islam Sultan Agung, Semarang, Indonesia; ${ }^{5}$ Department of Pathological Anatomy, \\ Faculty of Medicine, Universitas Islam Sultan Agung, Semarang, Indonesia; ${ }^{6}$ Department of Pathology, Faculty of Medicine \\ and Health Sciences, Stem Cell and Immunity Research Group, Immunology Laboratory, Universiti Putra Malaysia, Selangor, \\ Malaysia
}

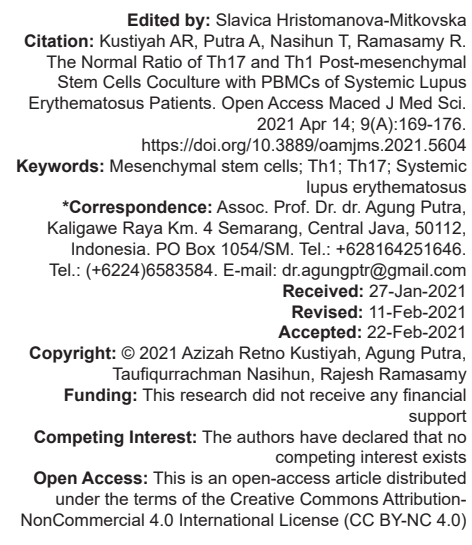

\section{INTRODUCTION}

Systemic lupus erythematosus (SLE) is a chronic autoimmune disease characterized by the production of autoantibodies and immune complex deposition in a wide range of tissues inducing chronic inflammation to failure organ function [1]. The clinical heterogeneity indicates the complexity of underlying pathogenic mechanisms of SLE that may induce the breakdown self-tolerance of the immune response leading to autoreactive lymphocytes to produce the autoantibody [2]. Although the autoreactive B lymphocytes are a major cell in inducing SLE pathogenesis, the altered T-cell population homeostasis has a pivotal role in developing the SLE disease [3]. The increase and expansion of Th17, a subset of $\mathrm{CD}^{+}$Th cells in target organs such as the kidneys, are associated with disease activity in mediating organ damage [4]. Th17/ $\mathrm{T}$ regulatory (Treg) ratio favoring Th17 cells as a consequence of cytokine imbalance may induce SLE flares and to be a hallmark of the SLE disease [5]. Although Th17 cells play a crucial role in SLE flares, Th1 cells are also involved in perpetuating those autoimmune processes. Th1 cells emerge as an effector response under IL-17 deficiency to constantly driving the clinical manifestation of autoimmune diseases and vice versa [6]. Therefore, controlling Th17 and Th1 using mesenchymal stem cells (MSCs) are needed to improve SLE flares because MSCs have immunosuppressive abilities to the autoreactive lymphocytes by generating Treg and releasing anti-inflammatory cytokines.

SLE is characterized by decreased function of Th1 and hyperfunction of Th2, which leads to excessive activation of B cells, generation of autoantibodies, and tissue injury [7]. Imbalance of Th subsets (Th1/Th2/ Th17) and regulatory Treg is suggested to contribute to the pathogenesis of SLE [8]. A previous study also demonstrated that an altered balance between Th1 and Th17 cells toward Th17 is due to a decreased percentages within the Th1 subset in SLE. On the other hand, SLE also characterized by an increased number 
of basophils (basophilia) and Th2-skewed immune reactivity has raised the fascinating hypothesis that disregarded Th2 may interplay with Th1-Th17 balance implicated in the pathogenesis of SLE [9], [10], [11].

MSCs are multipotent mesenchymal stromal cells characterized by expression of various surface markers such as CD73, CD90, CD105, and lack the expression of CD45, CD34, CD14 or CD11b, and CD79a or CD19. MSCs can also differentiate into specific cells such as chondrocytes, osteocytes, and adipocytes, making them an interesting cell source for application in regenerative medicine [12]. Another attractive potential of MSCs is their immunosuppressive ability in inhibiting the proliferation of $\mathrm{T}$ and $\mathrm{B}$ lymphocytes by releasing indoleamine 2,3-dioxygenase or nitric oxide, respectively, transforming growth factor $\beta 1$ (TGF- 31 ), prostaglandin E2 (PGE2), and IL-10 [13]. Several studies reported that MSCs may suppress the autoreactive $\mathrm{T}$ lymphocytes of SLE by generating Treg functional, CD4+CD25+high Foxp3+ (iTreg) through direct contact, or releasing TGF- $\beta 1$ and PGE2 [14], [15].

The intertwined and complex relationship between the Th1 and Th17 potentially induced the severe suffering patients of autoimmune disease including SLE. Reducing Th1 and Th17 cell subsets using MSCs may induce diminished inflammation leading to SLE improvement [4]. Our studies revealed that MSCs may inhibit the proliferation of Th1 and Th17 cells by inducing iTreg cells and releasing TGF- $\beta 1$, PGE2, and interleukin (IL-10) production in the supernatant of the cocultures [14], [15]. The emergence of MSCs-induced i-Treg in the inflammatory milieu of PBMC from SLE patients can suppress Th17 cell populations; however, Th1 cell population status as a response to the Th17 decrease remains unclear. Therefore, improving SLE flare by suppressing Th17 and constantly controlling Th1 under normal level through MSCs administration is crucial. In this study, we analyzed the role of MSCs in suppressing Th17 cell populations and controlling Th1 to a normal level by in vitro coculturing MSCs with PBMC from SLE patients.

\section{Materials and Methods}

\section{Research design}

This study was conducted in Stem Cell and Cancer Research (SCCR) Laboratory and approved by the committee ethic Institutional Review Board of Faculty of Medicine, Sultan Agung Islamic University, Semarang, Indonesia. The study design is a post-test control group design. All of the subjects, including 20 SLE patients and 5 healthy subjects and a pregnant donor for cord blood collection included in this study, were given and accepted the specific informed consent. The patient in this study was enrolled as an SLE patient on Dr. Kariadi Hospital, Semarang. The study period starts from November 28, 2020, until December 1, 2020 , after the isolation of PBMC on the $1^{\text {st }}$ day of study is continued with coculture PMBC and MSCs on $72 \mathrm{~h}$.

\section{Inclusion and exclusion criteria}

All SLE patients fulfilled the American College of Rheumatology (ACR) classification: SLE with antinuclear antibody-positive (ANA+), female patients, aged 15-50 years old, and SLE with severity mild to moderate. Exclusion criteria: Male patients, age $<15$ years, patients with any other immune deficient, and PBMC of the patient cannot fulfill or contaminated.

\section{MSCs isolation and culture}

MSCs were isolated and separated from cord blood as described previously (Putra et al. 2018) and cultured in Dulbecco's Modified Eagle Medium (DMEM) (Sigma-Aldrich, Louis St, MO) supplemented with $10 \%$ fetal bovine serum (FBS) (Gibco ${ }^{\mathrm{TM}}$ Invitrogen, NY, USA), $1 \%$ penicillin (100 U/mL)/streptomycin $(100 \mu \mathrm{g} / \mathrm{mL})$ (Gibco ${ }^{\mathrm{TM}}$ Invitrogen, NY, USA), and $0.25 \%$ amphotericin B (Gibco ${ }^{\mathrm{TM}}$ Invitrogen, NY, USA). These flasks then were incubated at $37^{\circ}$ and $5 \% \mathrm{CO}_{2}$. The medium was renewed every 3 days and the cells were passaged after reaching $80 \%$ confluency. The MSCs like at passage 5 were employed for the following experiments.

\section{MSCs marker characterization}

MSC-like surface antigens were analyzed by flow cytometry analysis at the fifth passage. After trypsinized and pelleted, the cells were subsequently incubated in the dark using allophycocyanin-, fluorescein isothiocyanate (FITC)-, phycoerythrin (PE)-, and PerCP-Cy5.5.1- mouse anti-human CD73, CD90, Lin, and CD105 antibodies (562245, BD Biosciences, CA, USA) for $30 \mathrm{~min}$ at room temperature in dark. The cells were rinsed twice using PBS. The analyses were performed using a BD Accuri C6 Plus flow cytometer (BD Bioscience) and postacquisition analyzed was calculated using BD Accuri C6 Plus software (BD Bioscience).

\section{Differentiation analysis}

\section{Isolation of PBMCs and MSCs co-culture}

The MSCs-like were cultured in a density of $1.5 \times 10^{\wedge} 4$ cells/well. The cells were grown in 24-well plate with standard medium containing DMEM (Sigma-Aldrich, Louis St, MO), supplemented with 10\% FBS (Gibco ${ }^{\text {TM }}$ Invitrogen, NY, USA), 1\% penicillin (100 U/mL)/streptomycin (100 $\mu \mathrm{g} / \mathrm{mL}) \quad$ (Gibco $^{\mathrm{TM}}$ 
Invitrogen, NY, USA), and $0.25 \%$ amphotericin $\mathrm{B}$ (Gibco ${ }^{\mathrm{TM}}$ Invitrogen, NY, USA) at $37^{\circ} \mathrm{C}$ and $5 \% \mathrm{CO}_{2}$. After reaching $95 \%$ confluency, standard medium was aspirated and replaced using osteogenic differentiation medium containing Mouse MesenCult ${ }^{\mathrm{TM}}$ Osteogenic Differentiation Basal Medium (Stem Cell Technologies, Singapore) with $20 \%$ Mouse MesenCult ${ }^{\mathrm{TM}}$ Osteogenic Differentiation $\times 5$ Supplement (Stem Cell Technologies, Singapore), $1 \%$ L-Glutamine (Gibco ${ }^{\mathrm{TM}}$ Invitrogen, NY, USA), $1 \%$ penicillin $(100 \mathrm{U} / \mathrm{mL}) /$ streptomycin $(100 \mu \mathrm{g} /$ $\mathrm{mL}$ ), and $0.25 \%$ amphotericin B. The differentiation medium was renewed every 3 days. After bone matrix formation occurred, calcium deposition was visualized using alizarin red staining (Sigma-Aldrich, Louis St, MO).

\section{Isolation of PBMCs and MSCs co-culture}

Human PBMCs were separated using FicollPaque (Sigma-Aldrich, Louis St, MO) from healthy volunteers with informed consent. PBMCs were cultured and expanded in RPMI 1640 (Gibco $^{\mathrm{TM}}$ Invitrogen, NY, USA), augmented with 10\% FBS, $100 \mathrm{U} / \mathrm{ml}$ penicillin and streptomycin, and $2 \mathrm{mM}$ glutamine. The cultured cells were incubated at $37^{\circ} \mathrm{C}$ in a humidified atmosphere with $5 \% \mathrm{CO}_{2}$. For the treatment group, PBMCs were cocultured with MSCs on a 24-transwell apparatus (Corning Inc.; Corning, New York, USA) in RPMI supplemented with $1 \%$ penicillin-streptomycin and 10\% FBS at MSCs: PBMCs ratio of 1:10, 1:25, and 1:40 (T1, T2, and T3; respectively) for $72 \mathrm{~h}$. On the other hand, for the sham and control group, the isolated PBMCs from normal and SLE patients, respectively, were cocultured in a 24-well plate (Corning) with the standard medium for $72 \mathrm{~h}$.

\section{Flow cytometry analysis}

According to the manufacturer's instructions, Th1 and Th17 markers in the PBMCs population were assessed by flow cytometry analysis after $72 \mathrm{~h}$ of incubation of MSCs. Before the marker incubation, the PBMCs were treated with BD GolgiStop ${ }^{\mathrm{TM}}$ (BD Bioscience) to terminate all transport protein process for $6 \mathrm{~h}$. The PBMCs were pelleted by centrifugation and washed using PBS. The cells were fixed using BD Cytofix ${ }^{\mathrm{TM}}$ Fixation Buffer for 10 min. For the staining of Th1 and Th17 markers, the cells were subsequently incubated using perCP-, FITC- and PE-conjugated anti-human CD4 (BD Bioscience) CD4, IFN- $\gamma$, and IL-17A, respectively. These cells were incubated for $30 \mathrm{~min}$ at room temperature in the dark. After surface marker antibody incubation, each sample was washed twice using PBS. The analysis was performed using a BD Accuri C6 Plus flow cytometer (BD Bioscience). A minimum of $1 \times 10^{4}$ gated events on forward scatter and side scatter were recorded for each sample. The post-acquisition analysis was conducted using the BD Accuri C6 Plus software (BD Bioscience, San Jose, CA, USA).

\section{Analysis of statistical}

Values were expressed as the mean \pm standard deviation (SD). The difference in the average between the study groups was examined by one-way parametric ANOVA test followed by post hoc Fisher's LSD. $p<0.05$ was considered statistically significant. All analyses were performed using SPSS statistical software version 23.0 (SPSS Inc., Chicago, IL).

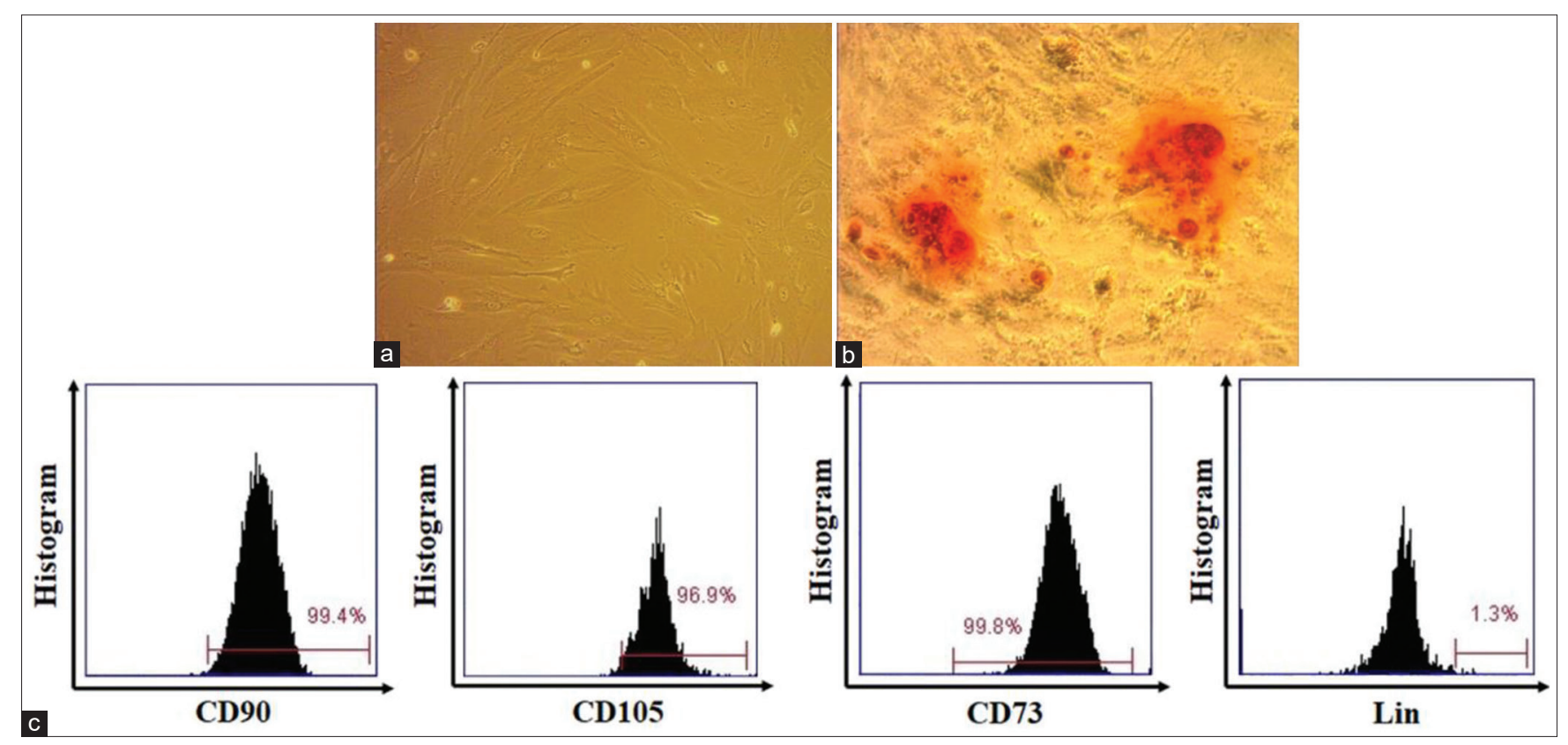

Figure 1: UC-MSCs candidate from the in vitro culture showed spindle form such as fibroblast-like cells $(\times 100)($ a), UC-MSCs were treated using an osteogenic differentiation medium to assess the capacity of MSCs to differentiate into the bone matrix. The calcium deposition appeared in red color after alizarin red staining (×200) (b), flow cytometry characterization of UC-MSCs expressed CD90, CD105, and CD73 and negatively expressed CD34, CD45, CD11b, CD19, and HLA-DR (c) 


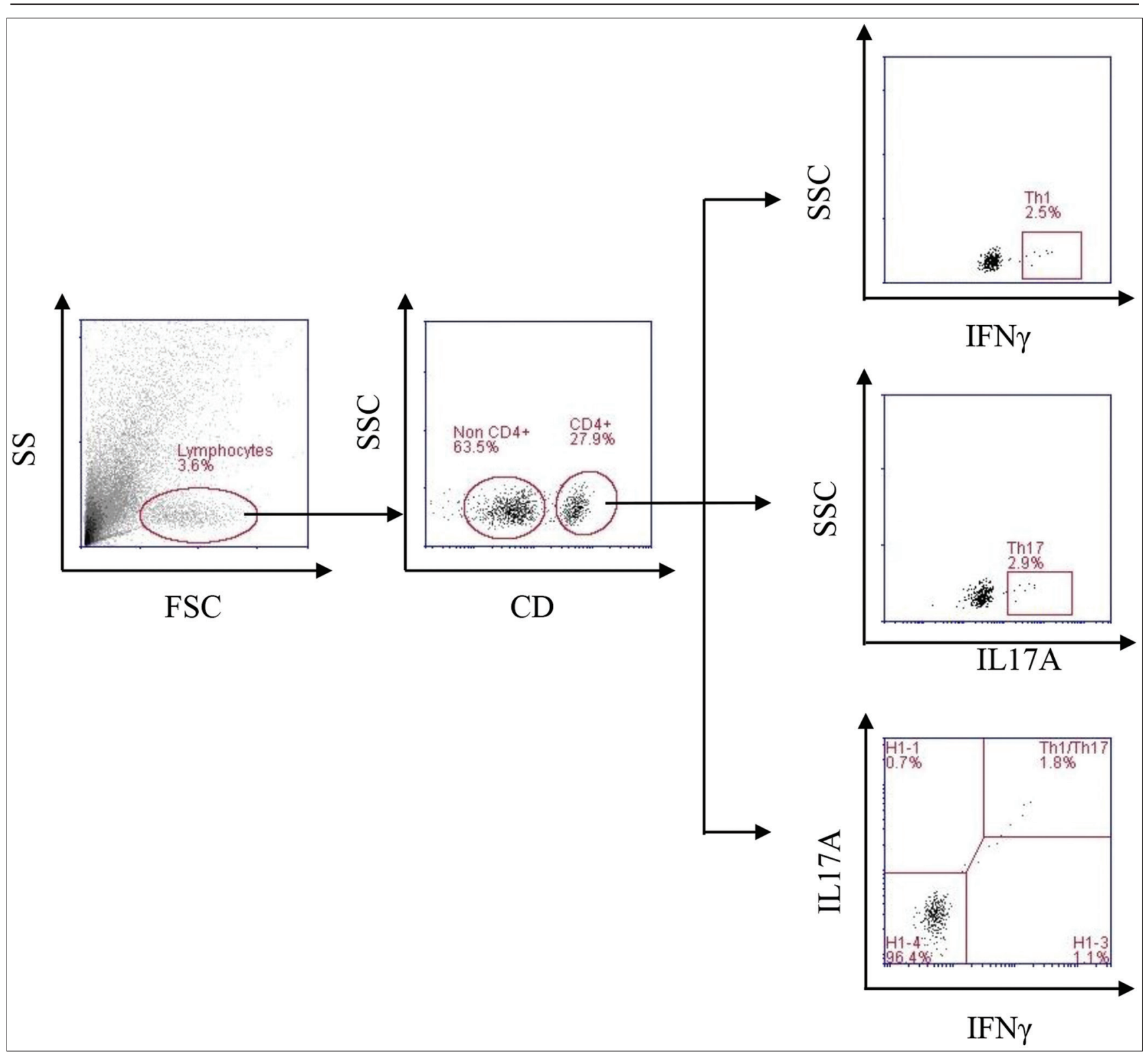

Figure 2: A gating strategy for Th1, Th2, and Th1-like Th17 cells population from CD4 cells

\section{Ethical approval}

This study were approved and in accordance with the Commission on Test Animal Ethics, Faculty of Medicine, Sultan Agung Islamic University (UNISSULA), Semarang, Indonesia under No. 204/VI/2017/Komisi Bioetik.

\section{Results}

\section{Characterization and differentiation of} MSCs

MSCs-like were isolated from umbilical cord and cultured based on their plastic adherent capability under a standard culture condition. In this study, the cell morphology of MSCs exhibited typical monolayers of spindle-shaped, fibroblast-like cells, with adherent capability to the plastic flask (Figure 1a). Isolated cells were cultured for 2-3 weeks in monolayer and used for characterization and differentiation analysis after the fifth passages.

At the fifth passages, osteogenic differentiation assay was performed on MSCs-like by administrating osteogenic medium for 21 days. Calcium deposition was visualized in red color using alizarin red solution (Figure 1b). Moreover, the MSC-like surface antigens were analyzed using flow cytometry. In this study, we found a high level of CD90 $(99.7 \pm 2.3 \%)$, CD105 (95.1 $\pm 1.5 \%)$, and CD73 (99.4 $\pm 1.7 \%)$, and low level of CD34, CD45, CD11b, CD19, and HLA-DR, represented as Lin $(0.2 \pm 0.05 \%)$ (Figure $1 c)$. 


\section{MSCs did not affect Th1 cell population in the cocultured PBMCs}

The Th1, Th17, and Th1-like Th17 were defined

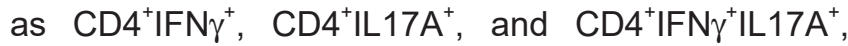
respectively (Figure 2). This study showed that MSCs did not affect the percentage of Th1 cells population in which there was no difference of $C D 4^{+} I F N \gamma^{+}$population in the PBMCs population after MSC treatment $(p>0.05)$ (Figure 3).

\section{MSCs inhibit Th17 cell population in the cocultured PBMCs}

This study showed that MSCs inhibit the percentage of Th17 cells population in which there was a significant decrease of $C D 4^{+} \mathrm{IL}_{17 A^{+}}$population in the PBMCs population on T1 group $(p<0.05)$ (Figure 4).

\section{MSCs inhibit Th1-like Th17 cell population in the cocultured PBMCs}

This study showed that MSCs inhibit the percentage of Th1-like Th17 cells population in which there was a significant decrease of CD4 ${ }^{+} I F N \gamma^{+} I L 17 A^{+}$ population in the PBMCs population on T1 group $(p<0.05)$ (Figure 5).

\section{Discussion}

The capacity of MSCs to control the autoreactive T-cells provided new insights into clinical use in SLE disease. The one autoreactive CD4+ Th cell population actively involving in SLE pathogenesis is a novel pathogenic Th17. However, to perpetuate the inflammatory response in SLE disease, Th1 is required. Th1 and Th17 cells may colocalize within the tissue site to induce inflammation [4], [5]. The previous studies have shown that MSCs have the ability to control inflammatory niches, depending on different mechanisms either by inducing iTreg or releasing several anti-inflammatory cytokines such as TGF- $\beta$, PGE2 and IL-10 [16]. T-cell immunosuppressive effects of MSCs in controlling Th17 and Th1 depend on the doses of MSC introduction to the inflammatory milieu in addition to the presence of other immune cells and the immune cells released soluble factor [17]. Other studies revealed that early MSCs administration into the autoimmune developing animal model might ameliorate those severity diseases, whereas later administration did not improve the imbalance of Th17 cells [18], [19]. To explore the potency of MSCs in controlling Th17 and Th1, we used in vitro model of the coculture of MSCs and PBMCs from SLE patients for $72 \mathrm{~h}$ of incubation with several doses.
This study showed that MSCs robustly suppress the proliferation, activation, and differentiation of Th17 following coculture with PBMC from SLE disease at high doses. In this case, the decrease of Th17 in PBMCs of SLE patients following coculture with MSCs headed into healthy people's normal levels. Interestingly, the decreased population of Th17 was in line with the appearance of IFN-Y expression on the treatment group. This indicated that the MSCs were not only controlling Th17 levels toward a homeostasis state; however, the MSCs also induce Th17 to Th1 conversion as well, which is a crucial point in improving the severity of the SLE disease. Th17 is a pathogenic subset of effector CD4+ T cells that have a role in the perpetuation of lupus nephritis by releasing IL-17A and IL-17F for mostly nonlymphoid stimulation in producing the chemokine and cytokine milieu such as IL-6, granulocyte colonystimulating factor (G-CSF), granulocyte-macrophage CSF, matrix metalloproteinase, and cytokine-induced neutrophil chemoattractant to stimulate and attract the neutrophils to the site of inflammation. Therefore, under the normal level of Th17, the damaged tissue due to inflammation of neutrophils infiltration effect can be attenuated, leading to SLE improvement gradually occurred [20].

We suggested that the normal Th17 population in PBMC of SLE patients after MSCs treatment due to the emergence of i-Treg as reported by our previous study. These i-Treg cell phenotypes are different from natural Treg (nTreg) produced in the thymus early phase of life. However, the iTreg originates from activated T-cell populations when appropriate stimuli are present in the surrounding microenvironment [21]. Nevertheless, MSCs at moderate and low doses cannot suppress the Th17 population. We suppose the soluble molecules as appropriate stimuli, particularly TGF $\beta$ and IL-10 released by MSCs at those doses, are under low levels to induce the Fox-P3, as a specific functional marker of Treg cells. Furthermore, MSCs did not significantly decrease Th1 cells in PBMCs of SLE patients due to these Th1 cells were not extremly released IFN-y to give sufficient stimulation to MSCs. The elevated Th17 is associated with a decrease of Th1 as an immune response regulator to drive pathology [4], [5].

However, this study has several limitations such as many aspects of such deregulation of Th1 and Th17 in the course of the disease are still unexamined, and conclusive data of SLE patients pointing specific underlying mechanisms are lacking. Restoring the immune balance between Th17, Th1, and Treg cells may help achieving a better clinical response. The aforementioned data suggest that targeting Th17, Th1, and Treg cells for therapeutic purposes in SLE may be explored and further study is warranted to rigorously examine the effects of MSC Th1 and Th17 in vivo on SLE disease relevant immune responses in the context of carefully designed clinical trials. 


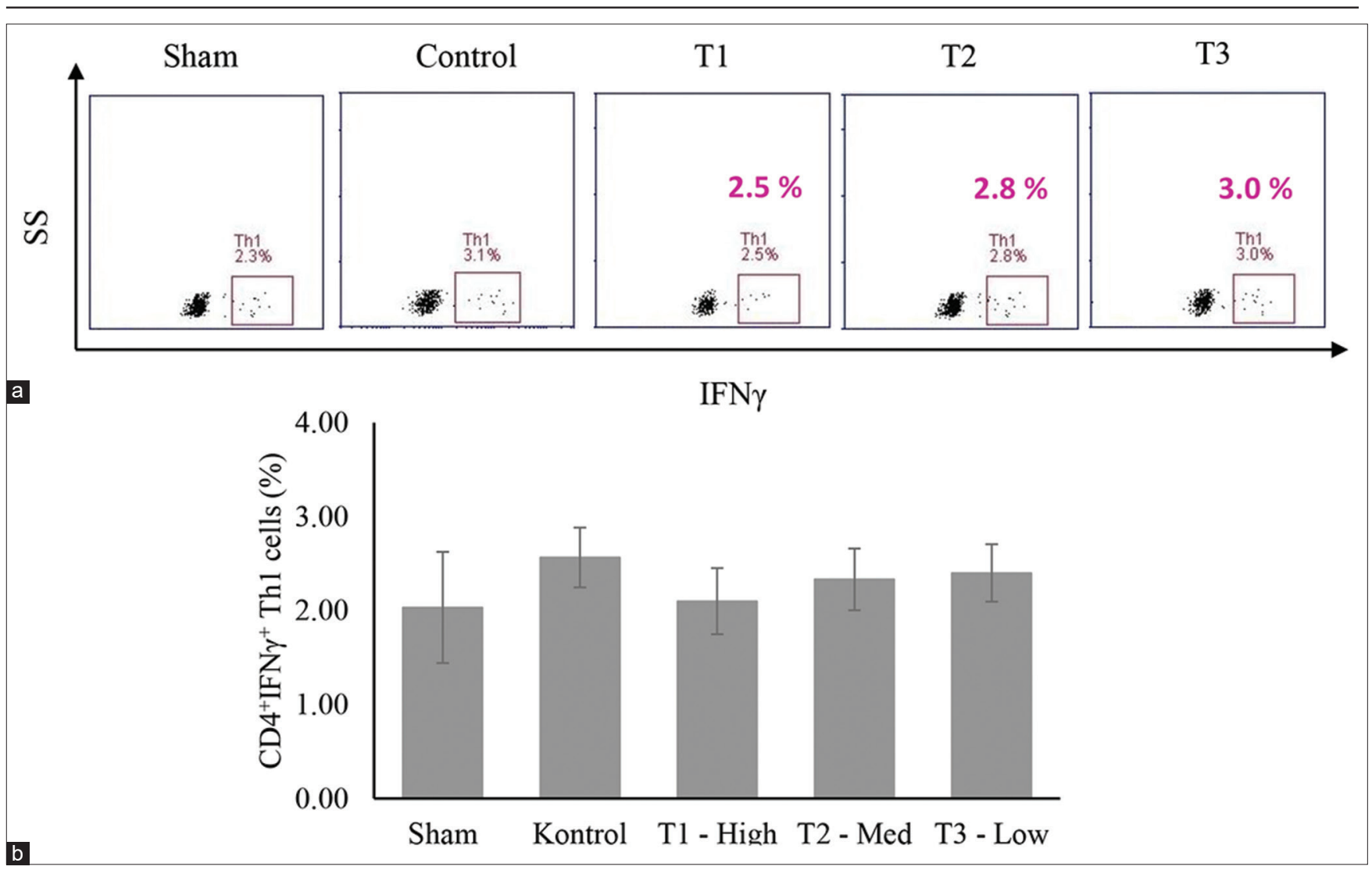

Figure 3: Flow cytometry analysis of Th1 cells in PBMCs with systemic lupus erythematosus after mesenchymal stem cells (MSCs) treatment and healthy control (a). The quantification of Th1 cells in (a); these experiments were repeated 3 times $\left({ }^{*} p<0.05\right)(b)$. Sham: Healthy patient or negative control; control: Incubated PBMC patients without MSCs; T1: Ratio of MSCs and PBMC of 1:1; T2: Ratio of MSCs and PBMC of 1:25; T3: Ratio of MSCs and PBMC of 1:50

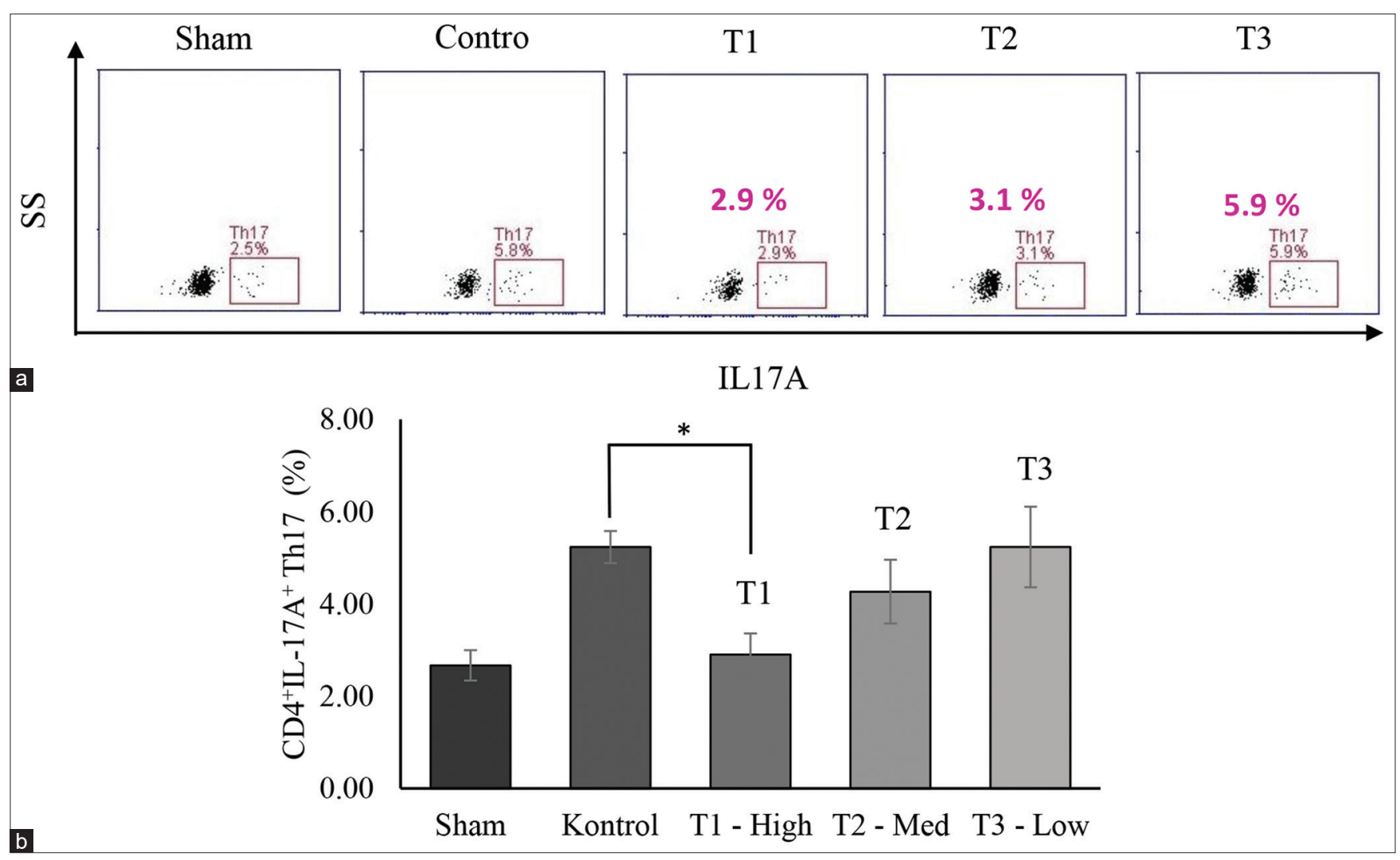

Figure 4: Flow cytometry analysis of Th17 cells in PBMCs with systemic lupus erythematosus after mesenchymal stem cells (MSCs) treatment and healthy control (a). The quantification of Th1 cells in (a); these experiments were repeated 3 times $\left({ }^{*} p<0.05\right)(b)$. Sham: Healthy patient or negative control; control: Incubated PBMC patients without MSCs; T1: Ratio of MSCs and PBMC of 1:1; T2: Ratio of MSCs and PBMC of 1:25; T3: Ratio of MSCs and PBMC of 1:50 


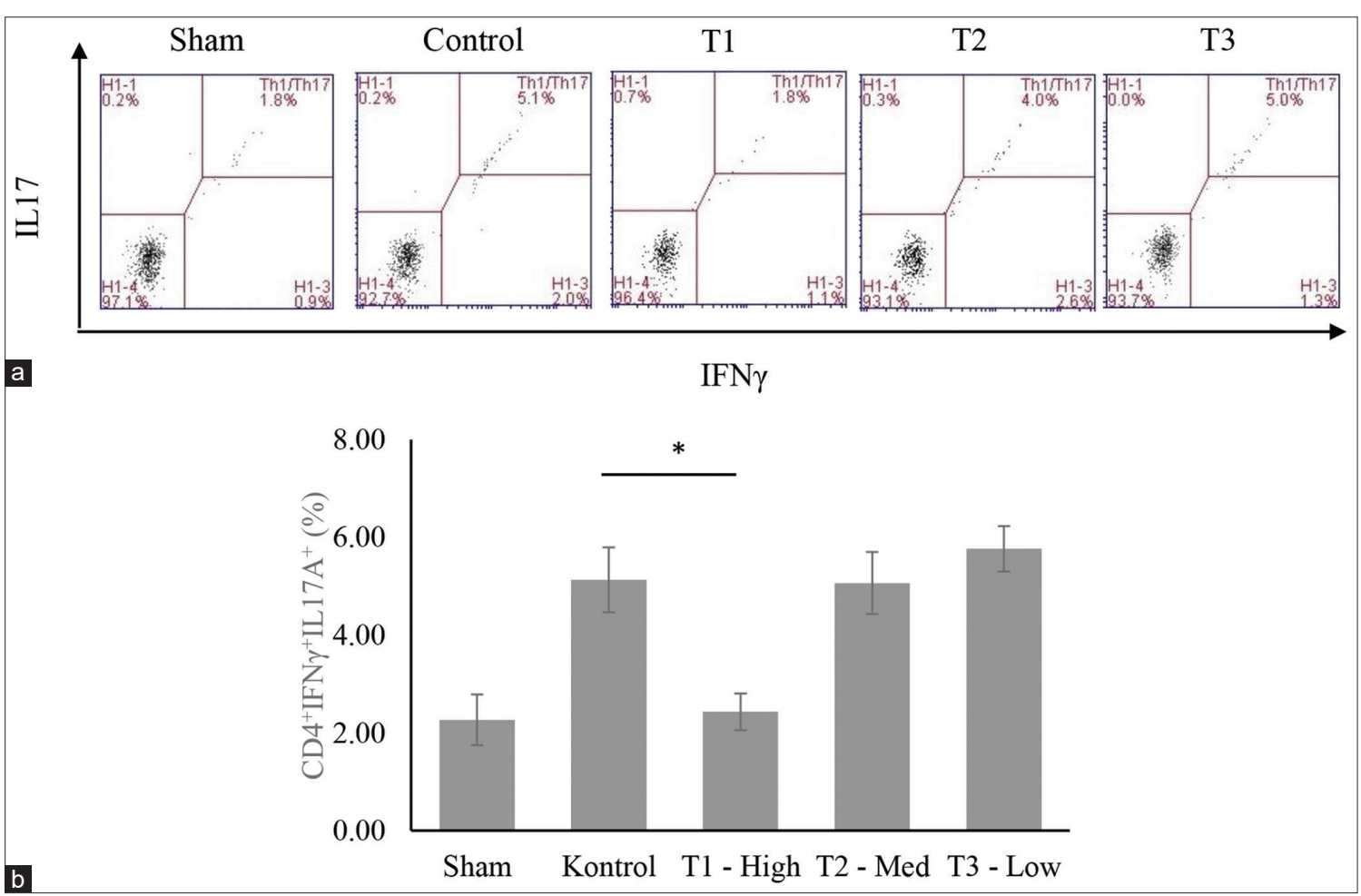

Figure 5: Flow cytometry analysis of Th1-like 17 cells in PBMCs with systemic lupus erythematosus after mesenchymal stem cells (MSCs) treatment and healthy control (a). The quantification of Th1 cells in (a); these experiments were repeated 3 times $\left({ }^{*} p<0.05\right)(b)$. Sham: Healthy patient or negative control; control: Incubated PBMC patients without MSCs; T1: Ratio of MSCs and PBMC of 1:1; T2: Ratio of MSCs and PBMC of 1:25; T3: Ratio of MSCs and PBMC of 1:50

\section{Conclusions}

MSCs may suppress Th17 and control Th1 to a normal level by in vitro coculturing MSCs with PBMC from SLE. Promising results concerning the effect of MSCs therapeutic targeting Th17 and Th1 balance may open new intrigues in investigating the future of new SLE treatment. Controlling aberrant T-cell homeostasis using MSCs is a crucial event in improving SLE pathogenesis, in which Th17, Th1, and Treg imbalance appear to represent a crucial key pathogenic player.

\section{Acknowledgment}

We would like to thank the SCCR Laboratory, the medical faculty at Sultan Agung Islamic University (Unissula), Semarang, Indonesia, and all who contributed to this research.

\section{Disclosure} this work.

\section{References}

1. Moulton VR, Suarez-FueyoA, Meidan E, LiH, Mizui M, Tsokos GC Pathogenesis of human systemic lupus erythematosus: $A$ cellular perspective. Trends Mol Med. 2017;23(7):615-35. https://doi.org/10.1016/j.molmed.2017.05.006

PMid:28623084

2. Choi J, Kim ST, Craft J. The pathogenesis of systemic lupus erythematosus-an update. Curr Opin Immunol. 2012;24(6):651-7.

PMid:23131610

3. Comte D, Karampetsou MP, Tsokos GC. T cells as a therapeutic target in SLE. Lupus. 2015;24(4-5):351-63. https://doi. org/10.1177/0961203314556139

PMid:25801878

4. Shah K, Lee WW, Lee SH, et al. Dysregulated balance of Th17 and Th1 cells in systemic lupus erythematosus. Arthritis Res Ther. 2010;12(2):R53. https://doi.org/10.1186/ar2964

PMid:20334681

5. Alunno A, Bartoloni E, Bistoni O, Nocentini G, Ronchetti S, Caterbi $\mathrm{S}$, et al. Balance between regulatory $\mathrm{T}$ and Th17 cells in systemic lupus erythematosus: The old and the new. Clin Dev Immunol. 2012;2012:823085. https://doi. org/10.1155/2012/823085 PMid:22761634

6. Tabarkiewicz J, Pogoda K, Karczmarczyk A, Pozarowski P, Giannopoulos K. The role of il-17 and th17 lymphocytes in autoimmune diseases. Arch Immunol Ther Exp (Warsz). 2015;63(6):435-49. https://doi.org/10.1007/s00005-015-0344-z PMid:26062902.

7. Pan L, Lu MP, Wang JH, Xu M, Yang SR. Immunological pathogenesis and treatment of systemic lupus erythematosus. 
World J Pediatr. 2020;16(1):19-30. https://doi.org/10.1007/ s12519-019-00229-3 PMid:30796732

8. Talaat RM, Mohamed SF, Bassyouni IH, Raouf AA. Th1/Th2/ Th17/Treg cytokine imbalance in systemic lupus erythematosus (SLE) patients: Correlation with disease activity. Cytokine. 2015;72(2):146-53. https://doi.org/10.1016/j.cyto.2014.12.027 PMid:25647269.

9. Dossybayeva K, Abdukhakimova D, Poddighe D. Basophils and systemic lupus erythematosus in murine models and human patients. Biology. 2020;9(10):308. https://doi. org/10.3390/ biology9100308 PMid:32977704.

10. Pan Q, Gong L, Xiao H, Feng Y, Li L, Deng Z, et al. Basophil activation-dependent autoantibody and interleukin-17 production exacerbate systemic lupus erythematosus. Front Immunol. 2017;8:348. PMid:28396669.

11. Poddighe D, Marseglia GL. Commentary: Basophil activationdependent autoantibody and interleukin-17 production exacerbate systemic lupus erythematosus. Front Immunol. 2017;8:787. PMid:28736553

12. Baghaei K, Hashemi SM, Tokhanbigli S, Rad AA, AssadzadehAghdaei $\mathrm{H}$, Sharifian $\mathrm{A}$, et al. Isolation, differentiation, and characterization of mesenchymal stem cells from human bone marrow. Gastroenterol Hepatol Bed Bench. 2017;10(3):208-13. PMid:29118937

13. Gebler A, Zabel O, Seliger B. The immunomodulatory capacity of mesenchymal stem cells. Trends Mol Med. 2012;18(2):12834. https://doi.org/10.1016/j.molmed.2011.10.004 PMid:22118960

14. Darlan DM, Munir D, Putra A, Jusuf NK. MSCs-released TGF $\beta 1$ generate $\mathrm{CD} 4+\mathrm{CD} 25+\mathrm{Foxp} 3+$ in T-reg cells of human SLE PBMC. J Formos Med Assoc. 2021;120(1 Pt 3):602-8. https:// doi.org/10.1016/j.jfma.2020.06.028 PMid:32718891

15. Ikhsan R, Putra A, Munir D, Darlan DM, Suntoko B, Kustiyah AR, et al. Mesenchymal stem cells induce regulatory T-cell population in human SLE. BJMS 2020;19(4):743e8. https://doi. org/10.3329/bjms.v19i4.46635

16. Putra A, Ridwan FB, Putridewi Al, Kustiyah AR, Wirastut $\mathrm{K}$, Sadyah NA, et al. The role of TNF- $\alpha$ induced MSCs on suppressive inflammation by increasing TGF- $\beta$ and IL-10. Open Access Maced J Med Sci. 2018;6(10):1779-83. https://doi. org/10.3889/oamjms.2018.404 PMid:30455748

17. Luz-Crawford P, Kurte M, Bravo-Alegría J, Contreras R, NovaLamperti E, Tejedor G, et al. Mesenchymal stem cells generate a CD4+CD25+Foxp3+ regulatory $T$ cell population during the differentiation process of Th1 and Th17 cells. Stem Cell Res Ther. 2013;4(3):65. https://doi.org/10.1186/scrt216

PMid:23734780

18. Wang D, Huang S, Yuan X, Liang J, Xu R, Yao G, et al. The regulation of the Treg/Th17 balance by mesenchymal stem cells in human systemic lupus erythematosus. Cell Mol Immunol. 2017;14(5):423-31. https://doi.org/10.1038/cmi.2015.89 PMid:26435067

19. Geng L, Tang X, Wang S, Sun Y, Wang D, Tsao BP, et al Reduced Let-7f in bone marrow-derived mesenchymal stem cells triggers Treg/Th17 imbalance in patients with systemic lupus erythematosus. Front Immunol. 2020;11:233. https://doi. org/10.3389/fimmu.2020.00233 PMid:32133007

20. Kolls JK, Lindén A. Interleukin-17 family members and inflammation. Immunity. 2004;21(4):467-76. https://doi. org/10.1016/j.immuni.2004.08.018

PMid: 15485625

21. Valmori D, Raffin C, Raimbaud I, Ayyoub M. Human ROR $\gamma t+$ TH17 cells preferentially differentiate from naive Foxp3+Treg in the presence of lineagespecific polarizing factors. Proc Natl Acad Sci U S A. 2010;107(45):19402-7. https://doi.org/10.1073/ pnas. 1008247107

PMid:20962281 